\title{
Susceptibility Testing of Mycobacterium frederiksbergense Strains Isolated from Alfalfa Plants against Antibacterial Compounds
}

\author{
Mirkaveh Mousaviehzadeh, Soroush Sardari* \\ Drug Design and Bioinformatics Unit, Medical Biotechnology Department, Biotechnology Research Center, \\ Pasteur Institute of Iran, Tehran, Iran \\ Email: ssardari@hotmail.com
}

Received 2 May 2015; accepted 2 June 2015; published 5 June 2015

Copyright (C) 2015 by authors and Scientific Research Publishing Inc. This work is licensed under the Creative Commons Attribution International License (CC BY). http://creativecommons.org/licenses/by/4.0/

(c) (i) Open Access

\section{Abstract}

Mycobacteria constitute vast population of bacteria that are found in animals, plants and outer environments. Tuberculosis mycobacteria are a group that causes very dangerous diseases for human and animals. Nontuberculous mycobacteria are mainly environmental and are pathogenic in certain circumstances. There are reports of finding mycobacteria in plant tissues, which can be effective to survey in case of different infectious disease issues. In a previous study, we found mycobacteria strains in alfalfa vascular tissues and identified them to species level using 16S rRNA gene sequence analysis, causing some symptoms in plant tissues and aerial parts. As these rapidly growing mycobacteria (RGM) have the potential to cause opportunistic infections in human tissues, one of the most important issues for dealing with these agents is to find the best and most effective drug to treat them. Here, we conducted some assays to investigate the MIC of 7 antibiotics and two antibacterial agents against eight Mycobacterium frederiksbergense alfalfa isolated strains, in order to find the susceptible and resistant ones. We performed susceptibility testing based on broth microdilution method using Mueller hinton broth as the medium used. Results were different among the strains and different resistant and susceptible reactions were observed among different strains against each drug tested, but ethambutol resulted in similar high MIC for all of them. This variability could be attributed to many factors, such as plant tissue composition and developmental stage from which the strains have been isolated, existence and nature of drug targets and other factors such as test conditions and environmental causes. These results can bring us some insights into design and develop new drugs for treating these kinds of organisms, based on the variations in susceptibility reactions and the plant composition effect on them.

"Corresponding author.

How to cite this paper: Mousaviehzadeh, M. and Sardari, S. (2015) Susceptibility Testing of Mycobacterium frederiksbergense Strains Isolated from Alfalfa Plants against Antibacterial Compounds. Open Journal of Medical Microbiology, 5, 90-96. http://dx.doi.org/10.4236/ojmm.2015.52011 


\section{Keywords}

\section{Nontuberculous mycobacteria, Opportunistic Infections, Mycobacterium frederiksbergense, Broth Microdilution}

\section{Introduction}

Mycobacteria are a group of bacteria that some of their species are very pathogenic to human and some animals. This genus of bacteria is divided into different categories, Tuberculosis mycobacteria which are very slow growing and nontuberculous which are slow and rapidly growing. Mycobacterium tuberculosis and Mycobacterium leprae are two very dangerous species that are the agents of lethal diseases, like tuberculosis and leprosy. Nontubercolous mycobacteria are mainly environmental [1] and occasionally have been observed for opportunistic infections in human tissues, especially hospital born infections [2]. Also, some of them are environmentally important, for example in bioremediation reactions [3]. Moreover, there are some reports of finding rapidly growing mycobacteria or RGM in plant species. In a recent study, we found Mycobacterium strains in alfalfa vascular tissues [4]. Other reports are as interference of Mycobacterium species with growth of Scots pine seedlings [5] and finding mycobacteria as hidden endophytes in shoot of rock plant [6]. Having indicated above, fast growing mycobacteria being belonged to "Group IV" of the Runyon classification are exceedingly being dissected as etiological factors of some infectious diseases, mostly pulmonary in patients having cystic fibrosis (Mycobacterium abscessus) and either public attained (Mycobacterium fortuitum) or cutaneous putrefaction accompanying health care issues (Mycobacterium chelonae) [7]. There is a big limitation on the antibiotic range for treatment of infections followed by these organisms and they are not strong. Consequently, new drugs are urgently needed to treat infections due to rapidly growing mycobacteria. Recently, tigecycline and to a less extent linezolid have been shown to have some in vitro activity against rapidly growing mycobacteria [8] [9].

Antimicrobial susceptibility testing is important for species that are considered clinically significant. The Clinical and Laboratory Standards Institute (CLSI) recently published guidelines and recommendations for testing of Nontuberculous mycobacteria. Broth micro dilution was recommended for isolates of rapidly growing mycobacteria [10]. Reliable analyzing of RGM, esp. strains that have been proven to have pathogenic effects on human tissues, is very important. One of the important issues about these types of mycobacteria is susceptibility testing of these agents against different antibacterial compounds for introducing most effective antibiotic. Plant associated mycobacteria which are either identified in the plant tissues or have some interaction to be infective for plants or have the potential to cause infections in animal cells, can consequently be good candidates for investigation in different analyses. As mentioned above, we identified some isolates of mycobacteria in alfalfa vascular tissues and also, some symptoms were observed in stem vascular inner tissues of alfalfa following $M y$ cobacterium inoculation which should be practiced more for confirmation of these observations. As a result, strains that could cause some infections in human tissues and also have some effects on plants structure and growth may have some characteristics that can grow and colonize in both plant and animal tissues.

In this study, we aimed to perform some susceptibility testing on a number of Mycobacterium isolates from alfalfa against some antibacterial agents that have been tested in clinical isolates of this species.

\section{Materials and Methods}

\subsection{Bacterial Strains}

Eight rapidly growing mycobacteriastrains were estimated in this experiment of plant origin, which previously isolated from alfalfa plants and identified to the species level as Mycobacterium frederiksbergense, using 16s rRNA gene sequence analysis [4]. They were purified and cultured by streaking on Corynebacterium agar (BioChemika, Germany) plates and 2 days fresh cultures in $30^{\circ} \mathrm{C}$ were used for susceptibility testing. Two strains, BCG (1173P, Pasteur Institute of Iran) and Mycobacterium smegmatis strain (PTCC 1307, Iranian Research Organization for Science and Technology) were used as reference strains.

\subsection{Antibacterial Agents}

The mentioned 8 isolates were evaluated for their susceptibility against nine antibacterial compounds as the fol- 
lowing: ethambutol, phenylglyoxal, isoniazid (Sigma, Germany), juglone, streptomycin (GibcoInvitrogen, USA) [11]-[14], ciprofloxacin, amikasin,imipenem and doxycycline (ParsDaru, Iran), which are commonly applied to treat $\mathrm{NTM}^{1}$ infections except juglone, which has been shown to have antibiotic effects on both fungi and bacteria [15].

\subsection{Susceptibility Testing}

Susceptibility testing was performed using broth microdilution method as the standard procedure for RGM [16]. Inocula were prepared from 48 hours broth cultures and wereadjusted to McFarland 0.5 turbidity by sterile distilled water and then diluted moreto reach a density of $1.5 \times 10^{5} \mathrm{cfu} / \mathrm{ml}$, when applied to the microplates, bacterial densitywas to $1.5 \times 10^{4} \mathrm{cfu} / \mathrm{ml}$. Mueller Hinton broth (Sigma, Germany)was used as the medium in this assay. Dosages of the compounds that were used in this study were $0.5 \mathrm{mg} / \mathrm{ml}$ for ethambutol andphenylglyoxal, $0.125 \mathrm{mg} / \mathrm{ml}$ for streptomycin, $0.062 \mathrm{mg} / \mathrm{ml}$ for isoniazid and juglone, $0.015 \mathrm{mg} / \mathrm{ml}$ for imipenem and doxycycline, and $0.007-0.015 \mathrm{mg} / \mathrm{ml}$ for amikasin and ciprofloxacin tothe first well. DMSO ${ }^{2}$ (Sigma, Germany) was applied as negative control to investigate the antibacterial activity of the compounds assayed. The microplates were incubated for 72 hours in $30^{\circ} \mathrm{C}$.

\section{Results}

Eight isolates from different fields in Hamadan province were analyzed. Results were examined visually based on the turbidity of bacterial cells in each column and the well without visual growth in each column was regarded as the MIC of each compound against mycobacterial isolates. The results are shown in Table 1.

Results presented in Table 1 indicate different susceptibility patterns among the 8 isolates against each drug tested, except ethambutol, which had the same MIC against all of the strains of Mycobacterium frederiksbergense. This variability fell into 3 groups for 5 of the antibiotics, 2 for three of them and MIC of ethambutol was the same for all the isolates.

The most powerful drug on these strains was ciprofloxacin. Among them, isolates 12, 32 and 53 showed highest susceptibility against ciprofloxacin and its MIC was $0.01 \mu \mathrm{g} / \mathrm{ml}$. The other 5 isolates with more resistant reactions were included in a MIC range of 0.03 to $0.06 \mu \mathrm{g} / \mathrm{ml}$.

The other antibiotic, to which most susceptibilities were observed was doxycycline, MIC against isolates 16 (1), 38, 24 and 14 was $0.06 \mu \mathrm{g} / \mathrm{ml}$, whilst for 3, 12 and 53 was $0.12 \mu \mathrm{g} / \mathrm{ml}$ and for 32, $0.24 \mu \mathrm{g} / \mathrm{ml}$. Amikasin with less effect had a MIC of 0.12 for 5 strains, except 16 (1), 24 and 53 with MIC's 0.97, 0.48 and 0.06, respectively and here 53 is regarded as the most susceptible one. For other 6 compounds, imipenem, streptomycin,

Table 1. MIC's ( $\mu \mathrm{g} / \mathrm{ml})$ of the 9 tested drugs and antibacterial compounds against the eight isolates.

\begin{tabular}{cccccccccccc}
\hline Compounds & \multicolumn{10}{c}{ Isolates } \\
& 3 & 12 & $16(1)$ & 38 & 14 & 32 & 24 & 53 & $\begin{array}{c}\text { M. smegmatis } \\
\text { (PTCC1307) }\end{array}$ & $\begin{array}{c}\text { BCG } \\
(1173 \mathrm{P})\end{array}$ \\
\hline Ethambutol & 15.62 & 15.62 & 15.62 & 15.62 & 15.62 & 15.62 & 15.62 & 15.62 & 0.094 & 0.8 \\
Isoniazid & 1.95 & 1.95 & 1.95 & 1.95 & 1.95 & 1.95 & 0.48 & 3.90 & 8 & 0.05 \\
Juglone & 1.95 & 1.95 & 1.95 & 1.95 & 1.95 & 3.90 & 1.95 & 1.95 & 1.50 & 0.78 \\
Phenylglyoxal & 31.25 & 31.25 & 31.25 & 31.25 & 62.5 & 62.5 & 62.5 & 31.25 & $>62.5$ & $>125$ \\
Streptomycin & 3.90 & 3.90 & 3.90 & 1.95 & 3.90 & 1.95 & 1.95 & 3.90 & 1.5 & 0.12 \\
Amikasin & 0.12 & 0.12 & 0.97 & 0.12 & 0.12 & 0.12 & 0.48 & 0.06 & 0.12 & 0.015 \\
Imipenem & 0.24 & 0.24 & 0.24 & 0.24 & 0.24 & 0.48 & 0.48 & 0.12 & 25 & 20 \\
Ciprofloxacin & 0.03 & 0.01 & 0.03 & 0.03 & 0.03 & 0.01 & 0.06 & 0.01 & 0.05 & 1.5 \\
Doxycyclin & 0.12 & 0.12 & 0.06 & 0.06 & 0.06 & 0.24 & 0.06 & 0.12 & 0.07 & 0.09 \\
\hline
\end{tabular}

\footnotetext{
${ }^{1}$ Nontuberculous mycobacteria.
}

${ }^{2}$ Dimethyl Sulfoxide. 
juglone, isoniazid, ethambutol and phenylglyoxal the susceptibility patterns was consistent with more resistant reactions and for two compounds ethambutol and phenylglyoxal, most strains were very resistant with high MIC's. AS a whole, isolates 53 and 24 showed the most susceptibility against all the compounds, except ethambutol for which the MIC was the same and isolate 3 was regarded as the most resistant bacterium. The results are shown in Table 1.

\section{Discussion}

Mycobacteria constitute a group of bacteria that are very important in regard of their impact on human health. Two major diseases influencing human tissues are tuberculosis and leprosy out of which tuberculosis is under strict focus, because of its high lethality in populations. Each year millions of people in the world die of tuberculosis, so there are many programs and projects for controlling these organisms. One of the main disease controlling projects that today are being performed in many clinical studies is searching for the most effective compounds and antibiotics on Mycobacterium tuberculosis. It has been under organized research now and before. Many researchers have performed analyses of the susceptibility of this bacterium against different compounds or under various trials to invent novel and fast protocols to best combat this terrible disease. Birinci et al (2002) in a study compared three susceptibility testing methods, MGIT, E-test and the proportion method and found no statistically significant difference between them [17]. Their results showed that MGIT and E-test methods are more applicable than the proportion method, because reaching the final result takes more time in proportion method than the two others. Martin et al. (2003) in an effort to examine second line drugs for suppression of multidrug resistant (MDR) TB, introduced a new susceptibility test method by using colorimetric method that was very faster, less expensive and more cost-effective than the proportion method and demonstrated that the results are well correlated with the proportion method [18].

Besides Mycobacterium tuberculosis which is very significant and falls into the slow growing category of mycobacteria, are the rapidly growing mycobacteria that are environmental. Occurrence of rapidly growing or atypical mycobacteria in different environments, soil, water [19], plants [6] [4] [20], human tissues (causing some infections) [19] indicates expanded ubiquity of these microorganisms. Some RGM species may be potential agents to initiate opportunistic infections in humans, such as Mycobacterium fortuitum, Mycobacterium chelonae and Mycobacterium abscessus group [19]. Mycobacterium abscessus and Mycobacterium fortuium are the agents of nontuberculous disorders in human that cause pulmonary infections. Some species like Mycobacterium smegmatis have been also depicted to give rise to rare pulmonary infections in human [21] [22].

As a rapidly growing environmental Mycobacterium species, $M$. frederiksbergense was found in alfalfa plants that had been sampled from different fields but from a same region [4]. The bacterium was isolated as an endophyte residing in inner vascular tissues of alfalfa. Also, it was observed that it may have formed some trace on the tissues from which it had been isolated. We aimed to analyze susceptibility reactions of some of the mentioned isolates to a variety of antibiotics and compounds that are currently used for suppressing M. tuberculosis and some other drugs. While, there are few reports of identification of Mycobacterium sp. in different plants and no previous documents for alfalfa, so considering different biological aspects of these alfalfa tissue isolated strains could be of great importance, especially that there are many reports of isolation of these rapidly growing species from human infected tissues and observation of opportunistic infective behavior for some of these species. In an article they have been shown to be potent of causing some cutaneous infections in humans [23]. Regarding the results of this experiment, these eight isolates presented different susceptibility responses against the antibiotics and compounds. Ranging from resistance to susceptible reactions, and also this variety was observed between isolates against one type of antibiotic. All the strains had the same susceptibilities against ethambutol. The most variable MIC belonged to amikasin, for which 4 different MIC values (ranging from 0.06 to 0.97 $\mu \mathrm{g} / \mathrm{ml}$ ) for the isolates were obtained. The other two antibiotics, to which the isolates showed most varied susceptibility values, were ciprofloxacin and doxycycline and 3 different MIC values were observed (ranging from 0.01 to $0.06 \mu \mathrm{g} / \mathrm{ml}$ forciprofloxacin and 0.06 to 0.24 for doxycycline). Imipenem and streptomycin was the two latter antibiotics having varied MIC values with three and two different values. The most powerful antibiotics against these isolates were ciprofloxacin, doxycycline and amikasin with MIC's ranging from 0.01 to $0.48 \mu \mathrm{g} / \mathrm{ml}$. Juglone was also effective against these strains with low MIC's.

The variability and differences in the susceptibilities of these isolates could be attributed to different reasons. Researches about endophytic organisms of plants have shown that different factors involving environmental and 
biological, like plant cultivar and age, type of tissues, etc have impacts on them [24]-[28]. Residing in the tissues of different varieties of alfalfa sown in some different fields could have brought some variations in the characteristics of this bacterium. They are isolated from the same plant species, but from different regions, so it may have been a relation between the plant composition variations and their effect on the susceptibility reactions of the strains isolated. Because of their isolation in different regions, there may have been a cause of climatic difference for these susceptibility variations; and the plant developmental stage or genotype from which these strains were isolated. Andreot et al. (2010) showed that type of bacterial media, different genotypes of plants and developmental condition, impact bacteria residing in roots of potato and some other endophytes [29]. Also, the interaction or antagonistic effects of other endophytic bacterial species may have affected these results. These varieties are noticed in the reactions of the isolates to the antibiotics to which they are susceptible and very susceptible, so impacts that the environment may have on them cannot be justified to direct them to more resistant types and it may have lead them to more susceptible reactions. These traits could have been the outcome of responses of the isolates against the plant environment and materials from which these strains have been isolated and alterations in genes controlling susceptibility or resistance reactions of the bacteria to the compounds tested. Because of these variations in the susceptibility responses, it would be a good idea to test more compounds and monitor the responses and choose the most susceptible organism and taking them into more investigations. Also, there would exist this possibility to extract some materials from alfalfa inner tissues and use them as some antibacterial compounds to test the susceptibility responses, especially alfalfa varieties from which the most susceptible ones are isolated and those varieties may have led these strains to be more susceptible genetically.

Taking into consideration the menacing role of tuberculosis mycobacteria for the health of world population and the significance and seriousness of finding most fruitful and fastest methods and solutions to challenge this bacterium and discovering novel and less worrisome remedies for infected patients and on the other part, the laboriousness and hazards of working with Mycobacterium tuberculosis has forced microbiologists to seek alternative agents and procedures to experiment combating tuberculosis.RGM also could be good candidates for investigation, both for themselves and for being an alternative for the experiments including Mycobacterium tuberculosis. Different works have been also done in order to test different antibiotics for susceptibility testing of Nontuberculous mycobacteria that may be infectious to human tissues [19] [23] [30]-[31]. As an instance, Mycobacterium smegmatis could be a good option and as a model organism in surveying Mycobacterium tuberculosis, because it shows similar susceptibility pattern as M. tuberculosis to some drugs [32] [33]. Another advantage of working with RGM is their rapid growing and giving more rapid results than tuberculosis.

\section{Conclusions}

According to these observations and previous works, it can be suggested that these environmental bacteria may have potentials in designing new strategies and remedies for medical microbiology especially that they have been found in both plant tissues and observed to have some trace on alfalfa vascular and also they can produce some opportunistic infections in human. Therefore, providing more information for their reactions to various compounds could be used as a model in designing new and more effective drugs against dangerous agents like Tuberculosis, as these phyto RGM grow faster and are less risky than M. tuberculosis. Hence, more researches on them could be safer than tuberculosis strains. In this case, investigation of their susceptibility responses and comparison with tuberculosis strains could be very effective and applicable.

By consideration this issue that Mycobacterium tuberculosis is a dangerous bacterium and slow growing and working with them in the laboratory is labor intensive, these $M$. frederiksbergense isolates might be investigated for application as model organisms as a replace for Mycobacterium tuberculosis. As these rapidly growing mycobacteria show various susceptibilities against the compounds tested, it can be proposed to recognize and isolate the genes responsible for these behaviors and use them as some models to target Mycobacterium tuberculosis strains.

\section{References}

[1] Holland, S.M. (2001) Nontuberculous mycobacteria. The American Journal of the Medical Sciences, 321, 49-55. http://dx.doi.org/10.1097/00000441-200101000-00008

[2] Fulkinham, J.O. (2002) Nontuberculous mycobacteria in the Environment. Clinics in Chest Medicine, 23, 529-551. 
http://dx.doi.org/10.1016/S0272-5231(02)00014-X

[3] Willumsen, P., Karlson, U., Stackebrandt, E. and Kroppenstedt, R. (2001) Mycobacterium frederiksbergense sp. nov., a Novel Polycyclic Aromatic Hydrocarbon Degrading Mycobacterium Species. International Journal of Systematic and Evolutionary Microbiology, 51, 1715-1722. http://dx.doi.org/10.1099/00207713-51-5-1715

[4] Deljou, A., Mousaviehzadeh, M.K., Ghasemi, A. and Rahimian, H. (2010) Identification of Mycobacterium sp. as an Alfalfa Root Bacterial Endophytes using 16S rRNA Gene Sequence Analysis. International Journal of Pharma and Bio Sciences, 2, 1-8.

[5] Laukkanen, H., Soini, H., Kontunen-Soppela, S., Hohtola, A. and Viljanen, M. (2000) A Mycobacterium Isolated from Tissue Cultures of Mature Pinus sylvestris Interferes with Growth of Scots Pine Seedlings. Tree Physiology, 20, 915920. http://dx.doi.org/10.1093/treephys/20.13.915

[6] Koskimaki, J.J., Hankala, E., Suorsa, M., Nylund, S. and Pirttila, A.M. (2010) Mycobacteria Are Hidden Endophytes in the Shoots of Rock Plant [Pogonatherum paniceum (Lam.) Hack.] (Poaceae). Environmental Microbiology Reports, 2, 619-624. http://dx.doi.org/10.1111/j.1758-2229.2010.00197.x

[7] Bastian, S., Brossier, F., Wichlacz, C., Jarlier1, V. and Veziris, N. (2010) Daptomycin Is Not Active against Rapidly Rrowing Mycobacteria. Journal of Medical Microbiology, 59, 135-136. http://dx.doi.org/10.1099/jmm.0.014274-0

[8] Brown-Elliott, B.A., Crist, C.J., Mann, L.B., Wilson, R.W. and Wallace, R.J. (2001) In Vitro Activity of Linezolid Against Slowly Growing Nontuberculous mycobacteria. Antimicrobial Agents and Chemotherapy, 47, 1736-1738. http://dx.doi.org/10.1128/AAC.47.5.1736-1738.2003

[9] Martin-de-Hijas, N.Z., Fernandez-Roblas, R., Fernandez-Martınez, A.I., Gadea, I. and Esteban, J. (2008) Usefulness of the Etest for Studying Tigecycline Susceptibility of Non-pigmented Rapidly Growing Mycobacteria. International Journal of Antimicrobial Agents, 32, 366-367. http://dx.doi.org/10.1016/j.ijantimicag.2008.04.016

[10] Clinical and Laboratory Standards Institute (2011) Susceptibility Testing of Mycobacteria, Nocardia and other Aerobic Actinomycetes. Approved Standard, Second Edition. CLSI Document M24-A2. Clinical and Laboratory Standards Institute, Wayne.

[11] Brown, T.J., Herrera-Leon, L., Anthony, R.M. and Drobniewski, F.A. (2005) The Use of Macroarrays for the Identification of MDR Mycobacterium tuberculosis. Journal of Microbiological Methods, 65, 294-300. http://dx.doi.org/10.1016/j.mimet.2005.08.002

[12] Somoskovi, A., Parsons, L.M. and Salfinger, M. (2001) The Molecular Basis of Resistance to Isoniazid, Rifampin, and Pyrazinamide in Mycobacterium tuberculosis. Respiratory Research, 2, 164-168. http://dx.doi.org/10.1186/rr54

[13] Makinen, J., Marttila, H.J., Marjamaki, M., Viljanen, M.K. and Soini, H. (2006) Comparison of Two Commercially Available DNA Line Probe Assays for Detection of Multidrug-Resistant Mycobacterium tuberculosis. Journal of Clinical Microbiology, 44, 350-352. http://dx.doi.org/10.1128/JCM.44.2.350-352.2006

[14] Katoch, V.M. (2004) Newer Diagnostic Techniques for Tuberculosis. The Indian Journal of Medical Research, 120, 418-428.

[15] Clark, A.M., Jurgens, T.M. and Hufford, C.D. (2006) Antimicrobial Activity of Juglone. Phytotherapy Research, 4, 1114. http://dx.doi.org/10.1002/ptr.2650040104

[16] Brown, B.A., Swenson, J.M. and Wallace, R.J. (1992) Broth Microdilution MIC Test for Rapidly Growing Mycobacteria. In: Isenberg, H.D., Ed., Clinical Microbiology Procedures Handbook, ASM Press, Washington DC, 5-11.

[17] Birinci, A., Coban, A.Y., Ekinci, B. and Durupinar, B. (2002) Comparison of the Proportion Method with Mycobacteria Growth Indicator Tube and E-Test for Susceptibility Testing of Mycobacterium tuberculosis. Memórias do Instituto Oswaldo Cruz, 97, 351-352. http://dx.doi.org/10.1590/S0074-02762002000300013

[18] Martin, A., Camacho, M., Portaels, F. and Palomino, J.C. (2003) Resazurin Microtiter Assay Plate Testing of Mycobacterium tuberculosis Susceptibilities to Second-Line Drugs: Rapid, Simple and Inexpensive Method. Antimicrobial Agents and Chemotherapy, 47, 3616-3619. http://dx.doi.org/10.1128/AAC.47.11.3616-3619.2003

[19] Agudo, L.G. and Martos, P.G. (2011) Clinical Significance and Antimicrobial Susceptibility of Rapidly Growing Mycobacteria. In: Mende-Vilas, A., Ed., Science against Microbial Pathogens: Communicating Current Research and Technological Advances, 363-377.

[20] Conn, V.M. and Franco, C.M.M. (2004) Analysis of the Endophytic Actinobacterial Population in the Roots of Wheat (Triticum aestivum L.) by Terminal Restriction Fragment Length Polymorphism and Sequencing of 16S rRNA Clones. Applied and Environmental Microbiology, 70, 1787-1794. http://dx.doi.org/10.1128/AEM.70.3.1787-1794.2004

[21] Gentry, C.A. (2005) Atypical Mycobacteria. In: Gentry, C.A., Ed., Pharmacotherapy Self-Assessment Program, 5th Edition, American College of Clinical Pharmacy, Kansas City, 99-126.

[22] Sharbati-Tehrani, S., Stephan, J., Holland, G., Appel, B., Niederweis, M. and Lewin, A. (2005) Porins Limit the Intracellular Persistence of Mycobacterium smegmatis. Microbiology, 151, 2403-2410. 
http://dx.doi.org/10.1099/mic.0.27969-0

[23] Regnier, S., Cambau, E., Meningaud, J.P., Guihot, A., Deforges, L., Carbonne, A., Bricaire, F. and Caumes, E. (2009) Clinical Management of Rapidly Growing Mycobacterial Cutaneous Infections in Patients after Mesotherapy. Clinical Infectious Diseases, 49, 1358-1364. http://dx.doi.org/10.1086/606050

[24] Adams, P.D. and Kloepper, J.W. (2002) Effect of Host Genotype on Indigenous Bacterial Endophytes of Cotton (Gossypium hirsutum L.). Plant Soil, 240, 181-189. http://dx.doi.org/10.1023/A:1015840224564

[25] Araujo, W.L., Maccheroni, W., Aguilar-Vildoso, C.I., Barroso, P.A., Saridakis, H.O. and Azevedo, J.L. (2001) Variability and Interactions between Endophytic Bacteria and Fungi Isolated from Leaf Tissues of Citrus Rootstocks. Canadian Journal of Microbiology, 47, 229-236. http://dx.doi.org/10.1139/w00-146

[26] Garbeva, P., Overbeek, L.S., Vuurde, J.W. and Elsas, J.D. (2001) Analysis of Endophytic Bacterial Communities of Potato by Plating and Denaturing Gradient Gel Electrophoresis (DGGE) of 16S rDNA-Based PCR Fragments. Microbial Ecology, 41, 369-383. http://dx.doi.org/10.1007/s002480000096

[27] Siciliano, S.D., Theoret, C.M., de Freitas, J.R., Hucl, P.J. and Germida, J.J. (1998) Differences in the Microbial Communities Associated with the Roots of Different Cultivars of Canola and Wheat. Canadian Journal of Microbiology, 44, 844-851. http://dx.doi.org/10.1139/w98-075

[28] Zinniel, D.K., Lambrecht, P., Harris, N.B., Feng, Z., Kuczmarski, D., Higley, P., Ishimaru, C.A., Arunakumari, A., Barletta, R.G. and Vidaver, A.K. (2002) Isolation and Characterization of Endophytic Colonizing Bacteria from Agronomic Crops and Prairie Plants. Applied and Environmental Microbiology, 68, 2198-2208. http://dx.doi.org/10.1128/AEM.68.5.2198-2208.2002

[29] Andreot, F.D., Rocha, U.N., Araujo, W.L., Azevedo, J.L. and Van Overbeek, L.S. (2010) Effect of Bacterial Inoculation, Plant Genotype and Developmental Stage on Root-Associated and Endophytic Bacterial Communities in Potato (Solanum tuberosum). Antonie van Leeuwenhoek, 97, 389-399. http://dx.doi.org/10.1007/s10482-010-9421-9

[30] Marušić, A. and Janković, M. (2012) Nontuberculous mycobacterial Pulmonary Disease. In: Amal, A., Ed., Pulmonary Infection, InTech, 55-68.

[31] Cardoso, A.M., Junqueira-Kipnis, A.P. and Kipnis, A. (2011) In Vitro Antimicrobial Susceptibility of Mycobacterium massiliense Recovered from Wound Samples of Patients Submitted to Arthroscopic and Laparoscopic Surgeries. Minimally Invasive Surgery, 2011, 1-4. http://dx.doi.org/10.1155/2011/724635

[32] McGaw, L.J., Lall, N., Hlokwe, T.M., Michel, A.L., Meyer, J.J. and Mand Eloff, J.N. (2008) Purified Compounds and Extracts from Euclea Species with Antimycobacterial Activity against Mycobacterium bovis and Fast-Growing Mycobacteria. Biological and Pharmaceutical Bulletin, 31, 1429-1433. http://dx.doi.org/10.1248/bpb.31.1429

[33] Nessar, R., Cambau, E., Reyrat, J.M., Murray, A. and Gicquel, B. (2012) Mycobacterium abscessus: A New Antibiotic Nightmare. The Journal of Antimicrobial Chemotherapy, 67, 810-818. http://dx.doi.org/10.1093/jac/dkr578 